\title{
Covid-19 Pandemic as a Contemporary Challenge and Determinant of EU Citizens' Priorities
}

\author{
Daniela Pastarmadzhieva $^{1^{*}}$, and Mina Angelova ${ }^{2}$ \\ ${ }^{1}$ University of Plovdiv Paisii Hilendarski, Department of Political Sciences and National Security, \\ 24 Tsar Asen Str., Plovdiv 4000, Bulgaria \\ ${ }^{2}$ University of Plovdiv Paisii Hilendarski, Department of Management and Quantitative Methods in \\ Economics, 24 Tsar Asen Str., Plovdiv 4000, Bulgaria
}

\begin{abstract}
The challenges caused by the Covid-19 pandemic have numerous dimensions. Although the public and the health care systems are the most affected by the situation, the indirect consequences may last longer. One of the areas, which has been put under stress is the relations between the society and the state. These relations determine the overall stability and performance of the states, which is also valid for supranational entity as the European Union (EU). In order to protect its stability, the member states of the latter need to respond the expectation and priorities of their citizens. Thus, the purpose of the current study is to identify if there is a change in the priorities of the EU citizens and what is it. The object of the study are the countries, members of the European Union, studied from 2016 to 2020. Focus of the research is the topics, most relevant for the citizens of EU member states. The data used is from Euro barometer and for the purposes of the analysis statistical methods (frequencies and cross tables) and comparative approach are used. The results show that generally the top priorities of the EU citizens are the same, but their intensity varies across the studied years.
\end{abstract}

\section{Introduction}

One of the factors determining the functioning of the states is the relations between the citizens and the state authorities. The behaviorist revolution institutionalized this aspect of the political process and draw the attention of the research on the citizens as a variable. Behavioral studies are more focused on the informal aspects of the political process and the behavior of individuals and political groups than on institutions and formal rules [1]. Furthermore, Almond and Verba [2] point out that a match is needed between the political culture and the political system in order for the latter to be stable. Thus, the policy-making process of the governments needs to be in compliance with the values, expectations and the priorities of the citizens.

This requirement is even more important to cover in the context of the Covid-19 pandemic as the situation may cause a social tension and instability. The relations between the state and

\footnotetext{
* Corresponding author: daniela.pastarmadzhieva@uni-plovdiv.bg
} 
the society determine the overall stability and performance of the states, which is also valid for supranational entity as the European Union (EU). In order to protect its stability, the member states of the latter need to respond the expectation and priorities of their citizens. Thus, the purpose of the current study is to identify if there is a change in the priorities of the EU citizens and what is it. The object of the study is the countries, members of the European Union, studied from 2016 to 2020 . Focus of the research is the topics, most relevant for the citizens of EU member states.

The data used is from Euro barometer and for the purposes of the analysis statistical methods (frequencies and cross tables) and comparative approach are used.

\section{Literature review}

When it comes to choices, behaviorism is a kind of counterpoint to the theory of rational choice. It uses the concept of limited rationality. Psychological methods are used, and the behavioral approach is also associated with surveys as a tool for examining political choices and attitudes, and in particular voter behavior. [3]

In this context the political culture theory gains popularity in the middle of the $\mathrm{XX}$ century. Reflections on political culture can be found as early as classical antiquity [4] but it was promoted in the contemporary political science by Gabriel Almond and Sydney Verba [2]. The authors discuss the processes in the new democracies and draw the attention to the fact that the formal institutions such as "universal suffrage, the political party, the elective legislature" are not enough. According to them, the democratic political system "requires a political culture as well consistent with it" [2]. The consistency of values with the system is a prerequisite for effective functioning of the government. The political culture consists of various elements but in general it is the psychological and subjective dimension of politics and is a product of both the collective history of a political system and the stories of the members of that system and is thus rooted equally in social events and personal experiences [5]. However, we can distinguish between two groups of elements in the structure of political culture - normative elements and axiological elements. The normative elements are the political traditions and norms, and the axiological ones are political values, political knowledge, political ideas and ideals [6]. All these taken together determine the behavior of the citizens in the political process.

On the basis of their political culture the citizens form their own priorities about the important issues of their countries. This is another aspect of the citizens role in the political process as it determines their preferences and expectations towards the political institutions. There are numerous variables, which can be used to assess the citizens' priorities and preferences. They can be attitudes towards the future of the country, responsibility for providing, importance of work and leisure time, work-life balance, quality of public services [7], public budget priorities such as healthcare, social protection, education, order and safety, environment, etc. [8]. Furthermore, it is not uncommon to examine the preferences and priorities of the EU citizens. Harrison et al. [7] examine the values, attitudes and preferences of the EU citizens and they identify associations between countries' GDP, age, income, and the examined variables. Thus, these factors influence the dynamics in the priorities and the next stage of the current research can be upgraded with the identification of similar associations.

As concern the income as a factor, its relevance is valid both on supranational and national level. On the one hand there is difference in the priorities of the rich and poor countries, and on the other these priorities vary across the rich and poor inside the countries. Such result is significant for the way the priorities turn into legislation and how the legislators react to people's demands [9]. People's income level may affect the agenda of the politicians to some 
level but alongside the politicians can influence the priorities, especially those groups who support them. [10]

The healthcare is traditionally important for most of the countries' citizens. However, it can have various aspects and one of them is related to the debate for personal responsibility for health. According to Schindler et al, "there was a tension between the lack of fault for having a disease, and the need for accountability for health behavior that influences solidarity and rising health costs". [10]

The prioritization of environmental issues is typically related to the development of postmaterialism. The environmental protection and focus on energy policies are more popular across Western Europe. The EU citizens from Central and Eastern Europe do not emphasize to such extent the environmental topics, especially in the area of energy policy [11].

\section{Materials and Methods}

For the purposes of the current study data from Euro barometer was used. The latter consists of the SPSS files of the following studies:

1)Standard Eurobarometer survey 85.2, performed in May 2016;

2)Standard Eurobarometer survey 87.3, performed in May 2017;

3)Standard Eurobarometer survey 89.1, performed in March 2018;

4)Standard Eurobarometer survey 91.2, performed in March 2019;

5)Standard Eurobarometer survey 93.1, performed in July-August 2020.

In our study we decided to focus on one single question, reflection the priorities of the citizens of the EU member states, namely "What do you think are the two most important issues facing (OUR COUNTRY) at the moment?". We intentionally selected the question regarding respondents' own country because the next step in our research will be to find association between the measures, taken on national level in each of the countries and the priorities of its citizens.

In accordance with the number of cases, only frequencies and cross tables were made, using the statistical software SPSS. Furthermore, comparative analysis was performed.

\section{Results and Discussion}

As a first step we aimed at identifying if there is a change on each of the priorities, listed by Euro barometer. It seems that Covid-19 pandemic did not change significantly the top priorities of the EU citizens and of the Bulgarians as well. The most significant areas for Bulgarians in 2016 were the unemployment, economic situation, health and rising prices/inflation/cost of living. Almost the same is average measured priorities for the all-EU citizens except for immigration, which is listed second in 2016. In 2020 the immigration is not among the top priorities anymore and the economic situation comes first, followed by the health issues. (Figure 1) 


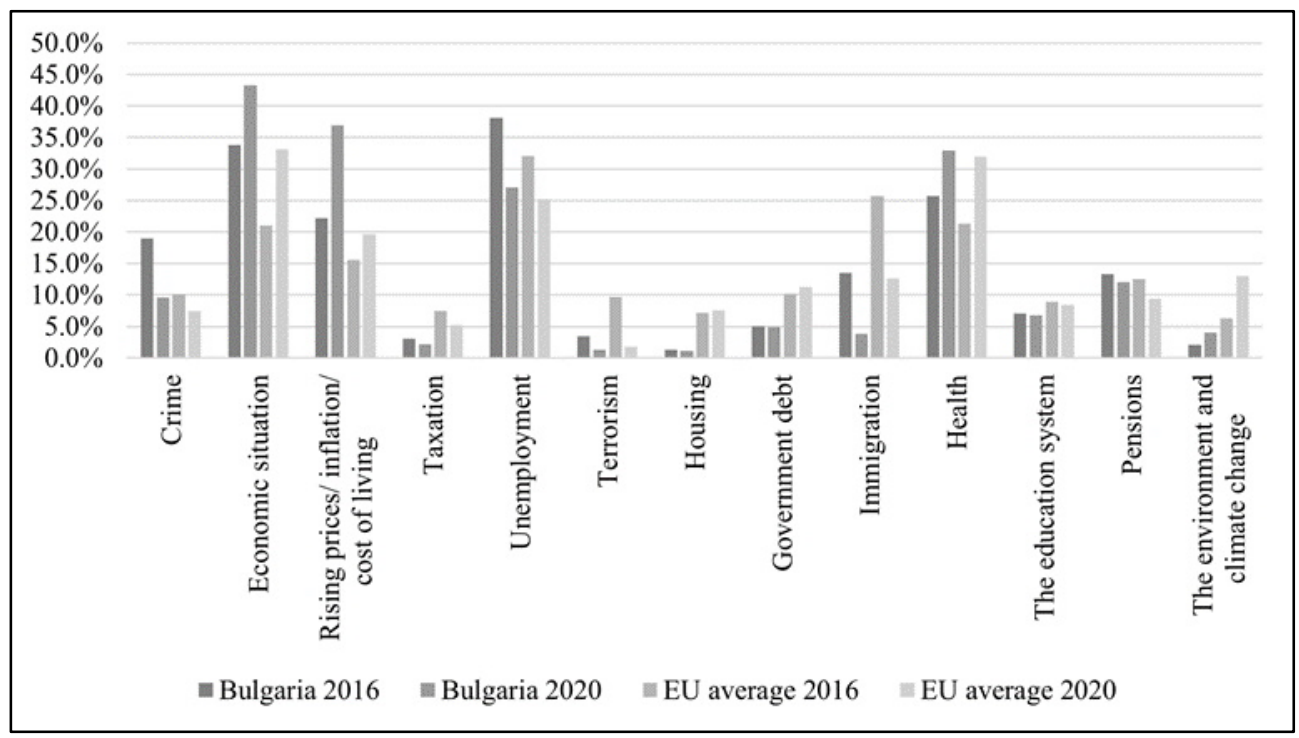

Fig. 1. Change in the priorities of the EU citizens in 2020 compared to 2016, Bulgaria and EU average

Source: Authors' calculations based on data from Eurobarometer 85.2 and Eurobarometer 93.1

Thus, we focused on four topics mostly prioritized by the EU citizens, namely economic situation, rising prices/inflation/cost of living, unemployment and health. The next figures show the dynamics in each of these priorities in the examined period for Bulgaria and the EU average.

In 2019 compared to 2016 there is a slight decrease in the prioritization of the economic situation. On the EU level it decreased from $21 \%$ to $16.8 \%$ and for Bulgaria the decrease is from $33.8 \%$ to $27.1 \%$. Obviously for Bulgarian citizen the topic is more significant compared to the EU average, but on both levels its importance decreased. However, the Covid-19 pandemic obviously changed the situation and in 2020 more EU citizens selected this topic as priority (33\%- EU average and $43 \%$ particularly in Bulgaria). (Figure 2 )

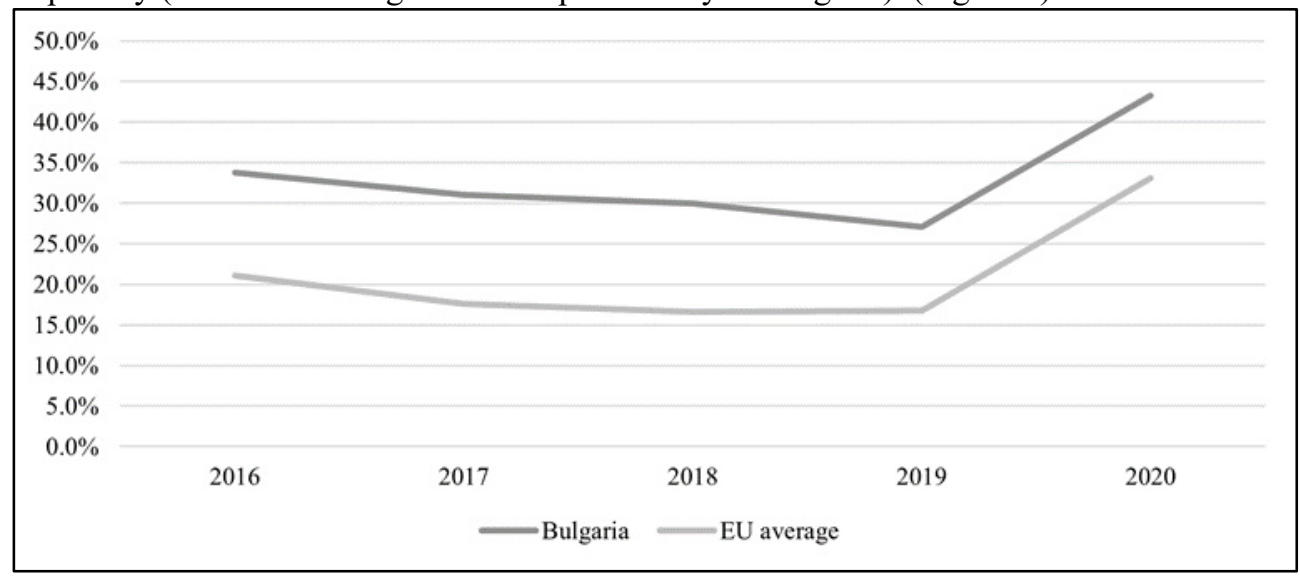

Fig. 2. Economic situation as a priority for the EU citizens, 2016-2020

Source: Authors' calculations based on data from Eurobarometer 85.2, 87.3, 89.1, 91.2 and 93.1

The results concerning the Rising prices/Inflation/Cost of living are rather interesting. These issues used draw the attention of the EU citizens increasingly in the period 2016-2020. 
In 2016 average $15.5 \%$ of the EU citizens and $22 \%$ of the Bulgarians in particular point it out as a priority. In 2019 this share increased to $22.4 \%$ for EU average and $41.1 \%$ for the Bulgarian citizens. In 2020 their share dropped down to $19.7 \%$ on EU level to $36.9 \%$ in Bulgaria. (Figure 3)

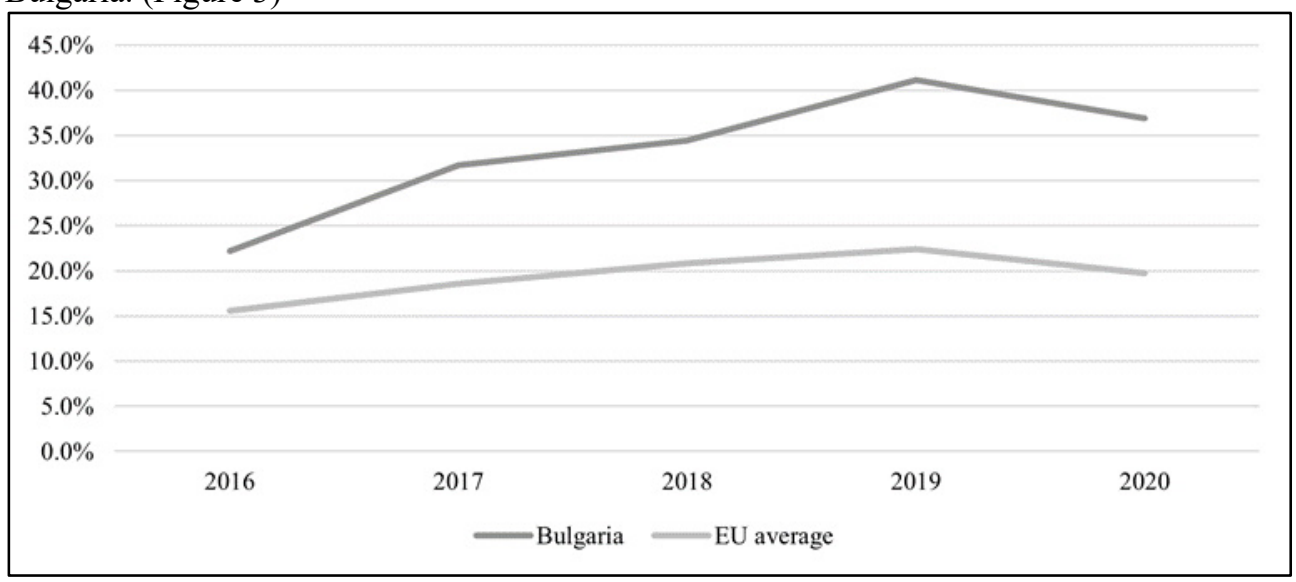

Fig. 3. Rising prices/Inflation/Cost of living as a priority for the EU citizens, 2016-2020

Source: Authors' calculations based on data from Eurobarometer 85.2, 87.3, 89.1, 91.2 and 93.1

Similarly, to the overall economic situation, the unemployment's significance decreased in 2019 compared to 2016. In Bulgaria, the share of people, who found it important in 2016 was $38.1 \%$ and the EU average was 32\%. In 2019 in Bulgaria, it decreased to $19.2 \%$ and in the EU average $-16.7 \%$. The effect of Covid-19 pandemic is visible here as well as in 2020 the share of respondents, who find this topic important increased to $27.1 \%$ in Bulgaria and to $25.2 \%$ in EU. (Figure 4)

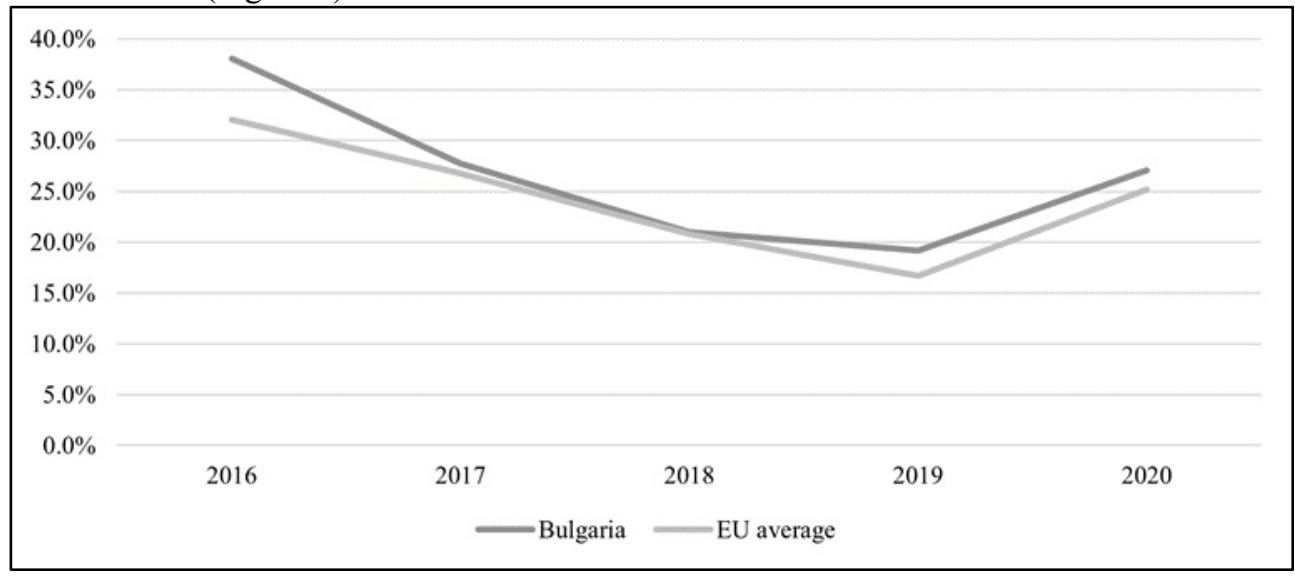

Fig. 4. Unemployment as a priority for the EU citizens, 2016-2020

Source: Authors' calculations based on data from Eurobarometer 85.2, 87.3, 89.1, 91.2 and 93.1

There is no surprise that the significance among the citizens increased in 2020. However, there is a growing trend for Bulgaria in particular since 2017. In 2017 24.6\% of the Bulgarians prioritize the health issues and in 2020 their share is $32.9 \%$. As concerns the EU average there isn't a specific trend, but the increase in 2020 compared to 2016 is from $21.3 \%$ to $32 \%$. (Figure 5) 


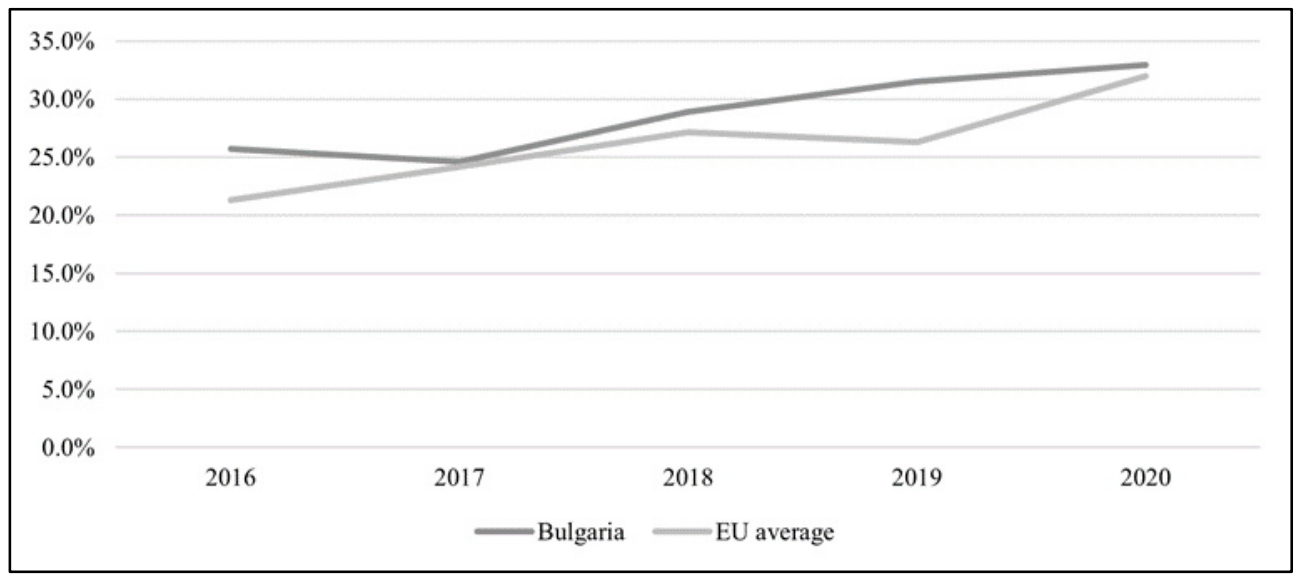

Fig. 5. Health as a priority for the EU citizens, 2016-2020

Source: Authors' calculations based on data from Euro barometer 85.2, 87.3, 89.1, 91.2 and 93.1

\section{Conclusion}

Traditionally, the EU citizens in general and Bulgarians in particular prioritize the economic situation, rising prices/inflation/cost of living, unemployment and the healthcare. During the initial stage of the pandemic, these priorities did not change, only some of them gained wider support. The worries about the health and the overall economic performance increased, while the concerns on more specific aspects such as inflation, rising prices, etc. decreased.

These initial results drew our attention to the fact the people are more anxious about some basic elements of the system. The current study demonstrates some initial and significant insights about the effect of Covid-19 pandemic on the priorities of the EU citizens. However, it will be supplemented by further data from the Euro barometer and with the identification of statistical associations between the priorities on the one hand and the measures and trust on the other.

The paper is part of a project № KP-06-DK-2/7/2021, funded by Bulgarian National Science Fund.

\section{References}

1. International Encyclopedia of The Social \& Behavioral Sciences - Vol. A-B, P. 1127

2. G. Almond, S. Verba, The Civic Culture: Political Attitudes and Democracy in Five Nations, (SAGE, 1989)

3. R. A. Dahl, The Am Pol Sci Rev, 55(4), 763 (1961)

4. J. Olick, T. Omeltchenko, Political culture, in: International Encyclopedia of The Social Sciences, 2nd ed., (Macmillan Library Reference, 2007)

5. L. Pye, Political culture, in: International Encyclopedia of the Social Sciences, The Macmillan Company and The Free Press, 12 (1968)

6. Bl. Blagoeva, Political culture and political socialization, in Fundamentals of political sociology, UI "Paisii Hilendarski”, Plovdiv (130-157) (2014)

7. E. Harrison, E. Sibley, S. Theodoropoulou, B. Guerzoni, What do citizens want? What survey results reveal about values, attitudes and preferences, EPC Issue Paper No 62 (2011) 
8. The Economist Intelligence Unit Limited, Priorities of Progress. Understanding citizens' voices, (2018),

https://www.nitto.com/others/about_us/gallery/prioritiesofprogress/pdf/whitepaper.pdf

9. P. Flavin, W. W. Franko, PSJ, 45(4), 659-687

10. M. Schindler, M. Danis, S. D. Goold and S. A., Health Expect, 21(5), 858-869 (2018)

11. D. M. Butler, H. J. G. Hassel, Am. Polit. Sci. Rev., 112(4), 1-14 (2018)

12. J. Tosun, M. Mišić, J. Eur. Integr., 42(1), 19-38 (2020)

13. European Commission, Brussels (2021), Eurobarometer 93.1 (2020). GESIS data archive, Cologne. ZA7649 data file version 1.1.0, https://doi.org/10.4232/1.13696.

14. European Commission, Brussels (2019), Eurobarometer 91.2 (2019). GESIS data archive, Cologne. ZA7562 data file version 1.0.0, https://doi.org/10.4232/1.13318.

15. European Commission, Brussels (2018), Eurobarometer 89.1 (2018). GESIS data archive, Cologne. ZA6963 data file version 1.0.0, https://doi.org/10.4232/1.13154.

16. European Commission, Brussels (2017), Eurobarometer 87.3 (2017). GESIS data archive, Cologne. ZA6863 data file version 1.0.0, https://doi.org/10.4232/1.12847.

17. European Commission, Brussels (2020), Eurobarometer 85.2 (2016). GESIS data archive, Cologne. ZA6694 data file version 2.0.0, https://doi.org/10.4232/1.13438. 